\title{
LXXIX. On Æthogen and Æthonides
}

\section{William H. Balmain}

To cite this article: William H. Balmain (1843) LXXIX. On Æthogen and Æthonides, Philosophical Magazine Series 3, 22:147, 467-470, DOI: 10.1080/14786444308636421

To link to this article: http://dx.doi.org/10.1080/14786444308636421

册 Published online: 01 Jun 2009.

Submit your article to this journal 준

III Article views: 3

Q View related articles $₫$ 
has rendered them to him complicated and confused. To account for the deposition of the metal upon the diaphragm, he is reduced to the necessity of supposing that " the metallic copper is to be attributed to the solutions acting (in some manner to me unintelligible) both as conductors and electrolytes."

According to my explanation the copper is arrested on its passage to the platinode by the impossibility of its combining even temporarily with the hydrate of potassa. In its state of oxide it is also arrested on account of its being insoluble. The metal, therefore, yields its charge to the hydrogen of the hydrate which is evolved in its place at the platinode. Both the copper of the sulphate and the oxygen of the hydrate are evolved upon the membrane and enter into secondary union, if there be time for the completion of the combination; but this secondary combination is not necessary to the electrolysis, and if the process be very rapid does not completely take place.
I remain, my dear Sir, very faithfully yours,
King's College, London,
J. F. Daniell. May $11,1843$.

\section{On Rthogen and AEthonides. By WILliaM H, BALMAIN*.}

$A^{\mathrm{T}}$ $T$ the commencement of the present year I made some experiments, with the hope of obtaining compounds of boron and silicon with nitrogen; and was successful so far as to obtain compounds consisting of boron and nitrogen together with certain metals, which are possessed of some very remarkable properties. The results of these experiments, with some remarks upon their bearing upon the science of chemistry, and a few facts proving the existence of analogous compounds of silicon and nitrogen, were published in the Phil. Mag. for October, 1842. Since that time I have succeeded in isolating the compound of nitrogen and boron, and have given it the name of Ethogen, from ai $\theta \omega v$ and yeivopal, because it produces, by uniting with the metals, compounds which glow with a peculiarly beautiful phosphorescent light when heated before the blowpipe in the oxidizing flame. And I think its compounds may with propriety be named Fthonides.

Preparation of AEthogen.-Heat to redness seven parts of finely powdered anhydrous boracic acid with nine parts of melon, in a crucible lined with charcoal; and immediately the

* Communicated by the Chemical Society; having been read December 6,1842 . 


\section{Mr. W. H. Balmain on Athogen and AEthonides.}

crucible is sufficiently cool to admit of being handled, rapidly transfer the light coherent powder which will be found in the interior, to a perfectly dry well-stoppered bottle.

Properties. - A white powder, light as prepared magnesia, infusible, and fixed at a white heat. Heated before the blowpipe it burns rapidly, giving the flame a green colour, but without phosphorescing. Exposed to air for a few seconds and then heated in a tube, it yields a palpable quantity of ammonia. Heated with hydrate of potass, it yields ammonia abundantly. It is not altered by hydrogen at a low red heat, nor by chlorine at ordinary temperatures, nor by the vapour of iodine; and it is insoluble in water, but communicates to it an alkaline reaction. It is decomposed with effervescence by nitric and sulphuric acids, and there remains after evaporation boracic acid. It deflagrates with chlorate of potass and with nitre. Heated to redness with potassium and zinc it yields æthonides of those metals.

Ethonide of Potassium. Preparation.-Take seven parts of finely powdered boracic acid and twenty parts of cyanide of potassium, free from water, and, as far as possible, from cyanate of potass and iron; and baving lined a Hessian crucible with a paste of powdered charcoal and gum, and heated it until all water has passed away, place the mixture in the crucible, cover it by inverting and luting a smaller crucible over it, and heat it to whiteness for an hour : it is advisable to use a crucible as a cover, that there may be sufficient room for spurious sublimation, and the rent-hole should be bored in the bottom of this crucible and not in the luting at the side; and further to avoid the penetration of oxygen to the materials, it is well to line the upper in like manner with the lower; or, by heating together potassium and æthogen avoiding an excess of potassium, and heating the result with nitric acid to free it from excess of æthogen.

Properties.-A light white solid, infusible and insoluble even when heated in water, in solution of potass, hydrochloric acid, sulphuric acid (strong and diluted), nitric acid, and solution of chlorine; it is not altered upon exposure to air, nor does it affect the most delicate turmeric paper when placed upon it in a moist state. Heated with hydrate of potass or soda, it yields ammonia abundantly. In the deoxidizing flame of the blowpipe it is not altered, nor does it communicate any colour to the flame: but in the oxidizing flame it gives a strong green colour, and gradually fuses, yielding a perfect bead which is transparent, hot and cold; and when placed with a drop of water upon test papers, turned turmeric brown and red litmus blue. When the outside flame impinges upon a large 
surface of the substance in powder, as when a glass tube soiled with it is held at the extreme point of the flame, it presents a beautiful green phosphorescence, owing no doubt to the formation of boracic acid at the surface, and if it be removed to the inner flame, the centre will incandesce, while the outer edges, where it meets with the oxygen of the air, will still yield the beautiful elegant green. When thrown upon fused chlorate of potass it deflagrates with a soft green light, and it will also deflagrate with nitrate of potass. It is not altered by being gently heated with potassium or sodium, nor when heated before the blowpipe on charcoal with lead, zinc, \&c. Chlorine has no action upon it at a low red heat, and iodine, sulphur and corrosive sublimate may be sublimed from it without decomposing it. It is not decomposed by hydrogen at a red heat, but below that temperature is decomposed with the evolution of ammonia by the vapour of water, or by any substance which will yield water, as hydrate of potass, hydrate of lime, common clay, hydrated phosphoric acid and the rhombic phosphate of soda. It is not decomposed by hydrochloric acid at a low red heat, and I think it is not altered by hydrofluoric acid, for a small portion of it was mixed with a large quantity of fluorspar, with more than sufficient sulphuric acid to make it all into hydrofluoric acid, and heated as long as fumes passed off, when, after the sulphate of lime had been washed away with dilute nitric acid, it still yielded ammonia with hydrate of lime.

Ethonide of Zinc. Preparation.-Heat together, to whiteness, in a lined crucible, one part of anhydrous boracic acid and two and a half parts of cyanide of zinc-or heat finely granulated zinc with æethogen to the temperature at which zinc sublimes, and wash the result with nitric acid.

Properties.-A white solid resembling the last, gives ammonia abundantly when heated with a mixture of hydrate of lime and carbonate of potass, and is insoluble (with or without heat) in water, sulphuric acid, hydrochloric acid, nitric acid, solution of potass and ammonia. It is not decomposed by chlorine or hydrogen at a full red heat, nor by corrosive sublimate, nor by potassium or sodium. Before the blowpipe it is infusible, but in the oxidizing flame communicates a green colour, and when at the outer edge emits a very brilliant bluish phosphorescence, which appearance it also produces when simply dropped into the flame of a spirit-lamp. Thrown on fused chlorate of potass, it deflagrates with a faint blue light.

Ethonide of lead may be obtained by heating chloride of lead with æathonide of zinc, or by heating boracic acid with 
cyanide of lead, or by heating together lead and æthogen. It phosphoresces with a green light.

Athonide of silver may be obtained by heating together chloride of silver and æthonide of zinc, or by heating together æthogen and silver. It is a light white solid, and is not acted upon by any of the re-agents with which it was tried, not even by chlorine or hydrogen at a full red heat. This compound phosphoresces with a peculiarly fine green light.

I believe I have obtained æthonides of several other metals by heating their chlorides with æethonide of zinc, but the quantities operated upon were too small to give certain results.

I am bound to apologize for sending in my results without an analysis, but the means of doing otherwise are not in my power, and I am in hopes that Dr. Kane will oblige us with more valuable data than I could furnish.

Liverpool, Nov. 28.

LXXX. Report of some Experiments with Saline Manures containing Nitrogen, conducted on the Manor Farm, Havering-atte-Bower, Essex, in the occupation of Collinson Hall, Esq. By W.M. F. ChatTerley*.

TNDUCED by the prevailing opinion that upon the quantity 1 of Nitrogen contained in some animal and saline manures, depend their fertilizing properties, it was decided to test, by experiment, the relative value of three saline manures containing that element as a constituent, viz. nitrate of potash, nitrate of soda, and sulphate of ammonia, all these salts, from their commercial price, being within the reach of the farmer for agricultural purposes, provided a sufficient amount of profit for the outlay can be shown, and that of course would be preferred by the agriculturist which yields the greatest profit on the prime expenditure.

For the purposes of the experiment a field of WHEAT was chosen, which in the latter end of April, 1842, presented a thin plant, the salts were top-dressed over the land by hand, on the 12th of May, in the quantities stated in the table below; the crop was mowed on the 10th of August, and the separate parcels taken from an eighth of an acre, threshed, measured, and weighed under my own inspection on the 24th of August. The results are as follow for the acre:-

* Communicated by the Chemical Society; having been read December 6, 1842. See Phil. Mag. S. 3. vol. xxi. p. 488. 